\title{
Yhteisen maatalouspolitiikan soveltamisen hyvinvointivaikutukset Suomessa
}

\author{
Jyrki Niemi \\ MTT Taloustutkimus (MTTL), Luutnantintie 13,00410 Helsinki, jyrki.niemi@mtt.fi
}

\section{Tiivistelmä}

Tämän tutkimuksen tavoitteena oli selvittää, miten EU:n yhteisen maatalouspolitiikan (YMP) soveltaminen on vaikuttanut Suomessa maataloustuotteiden tuottajien ja kuluttajien sekä veronmaksajien hyvinvointiin. YMP:n aiheuttamien hyvinvointivaikutusten määrittämiseksi vuosien 1995-2003 toteutunutta kehitystä on verrattu hypoteettiseen tilanteeseen, jossa Suomi olisi vuosina 1995-2003 ollut EU:n ulkopuolella ja jatkanut kansallisen maatalouspolitiikkansa harjoittamista. Hinta- ja tukipolitiikan muutosten vaikutuksia maataloustuotteiden tuotantoon ja kulutukseen on arvioitu staattisen kysyntätarjontamallin avulla. Hyvinvointivaikutukset on mitattu metodologisesti kuluttajan ja tuottajan hyvinvointifunktioista. Hyvinvoinnin mittarina on käytetty hyvinvointitalousteorian ylijäämäkäsitteitä: tuottajan ja kuluttajan ylijäämää. Taloudellisilla ylijäämäkäsitteillä on arvioitu euromääräisesti, kuinka paljon kukin ryhmä on politiikan muutoksen seurauksena hävinnyt tai voittanut.

Vaikka taloudellisia ylijäämäkäsitteitä on arvosteltu niiden puutteiden takia, ne ovat edelleen käyttökelpoinen tapa määrittää eri politiikkavaihtoehtojen vaikutukset yhteiskunnan eri ryhmien kannalta. Tuottajan ylijäämä ilmaisee viljelijän tuotantotoiminnastaan saaman voiton ja kiinteitä kustannuksia kattamaan jäävän osuuden kokonaistulosta. Kuluttajan ylijäämä kuvaa puolestaan hyödykkeen markkinahinnan ja kuluttajan maksuhalukkuuden välistä eroa. Vaikeutena hyvinvointianalyysin tekemisessä on tarvittavien kysyntä- ja tarjontafunktioiden estimointi. Tämä on yleensä rajoittava tekijä, koska hintasäätely sekä erilaiset ohjaus- ja tukijärjestelmät vääristävät maataloustuotteiden tarjonta- ja kysyntäreaktioita.

Tässä tutkimuksessa maatalousmarkkinoita on tarkasteltu kahdeksan eri maataloustuotteen osalta: maito, naudanliha, sianliha, siipikarjanliha, kananmunat, vehnä, ohra ja kaura. Näiden tuotteiden osuus Suomen maatalouden markkinahintaisesta tuotosta oli vuonna 2003 yli $90 \%$. EU-jäsenyyden vaikutusten saamiseksi esille on tarjonnan ja kysynnän joustojen avulla konstruoitu ensin hypoteettiset estimaatit kulutuksen ja tuotannon määrille, jotka olisivat toteutuneet ilman EU-jäsenyyttä. Saatujen estimointitulosten pohjalta on sen jälkeen määritelty tuottajien, kuluttajien ja veronmaksajien hyvinvointimuutokset integraalilaskennan avulla.

Tutkimuksen mukaan tuottajat ovat kärsineet noin 570-600 miljoonan euron hyvinvointitappion EU-jäsenyyden seurauksena. Kuluttajat ovat sitä vastoin saaneet yhteensä 815-875 miljoonaa euroa hyvinvointivoittoa maataloustuotteiden hintojen laskun myötä. Valtion varoista maksettujen tukien lasku on puolestaan tuottanut veronmaksajille noin 470-580 miljoonaa euroa hyvinvointivoittoa. Veronmaksajien hyvinvointivoitto on seurausta muun muassa vientikustannusmaksujen siirtymisestä EU:n budjetin kautta rahoitettaviksi. Koko yhteiskunnalle on koitunut EU-jäsenyyden seurauksena noin 500-700 miljoonaa euroa hyvinvointivoittoa.

Asiasanat: EU, yhteinen maatalouspolitiikka, integraatio, hyvinvointitalousteoria 


\section{Johdanto}

Maa- ja elintarviketalouden toimintaympäristö muuttui radikaalisti vuoden 1995 alussa, kun elinkeino siirtyi EU:n yhteisen maatalouspolitiikan (YMP) markkina- ja ohjausjärjestelmien piiriin Suomen EUjäsenyyden toteuduttua. Sitoutuminen yhteiseen maatalouspolitiikkaan merkitsi suomalaiselle maa- ja elintarviketaloudelle lyhyessä ajassa ennennäkemättömän suurta taloudellisen toimintaympäristön muutosta. EU-jäsenyyden myötä maataloustuotteiden markkinahintojen tasoa ei voitu enää entiseen tapaan säädellä kansallisella rajasuojalla ja vientituella. Elintarvikeketjun hallinnollisen ohjauksen tilalle tuli suurempi markkinaohjautuvuus. Vapaa tuonti ja vienti EU-maiden kesken pakottivat niin maatalouden kuin elintarviketeollisuudenkin toimimaan markkinoilta tulevien tarpeiden mukaan.

EU-jäsenyyden myötä elintarvikkeiden hinnat putosivat keskimäärin 11 prosenttia, vaikka arvonlisäveroa korotettiin 12:sta 17:ään prosenttiin. Hinnanalennuksen aiheutti se, että maatalouden tuottajahinnat laskivat muiden jäsenmaiden tasolle ja elintarvikkeiden tuonti muista EU-maista vapautui. Ruoan hintakehitys on ollut koko EU-jäsenyysajan maltillista. Vuodesta 1995 vuoteen 2004 ruuan hinta on kallistunut nimellisesti $11 \%$. Yleinen kuluttajahintaindeksi on samassa ajassa noussut 13,4 \%, joten ruuan reaalinen hinta on pysynyt alle vuoden 1995 tason (Niemi ja Ahlstedt 2005).

Maatalouden tuottajahintataso aleni Suomessa keskimäärin 40 \% heti vuoden 1995 alussa. Tuotantopanosten hintojen aleneminen ei riittänyt kattamaan kokonaistuoton laskua, joten alenevia tuottajahintoja ja pohjoisista luonnonolosuhteista aiheutuvia haittoja on kompensoitu erilaisilla tuilla. Maatalouteen kohdistuvalla tuella sekä sen luonteella ja määrällä onkin Suomessa keskeinen rooli maatalouden kilpailuedellytysten turvaamisessa maan eri osissa ja tuotantosuunnissa. Vuonna 2004 tukien kokonaismäärä nousi 1,8 mrd. euroon, mikä vastaa $45 \%$ maa- ja puutarhatalouden kokonaistuotosta (3,97 mrd. euroa). Maatalouden tulot ovat tukien kasvusta huolimatta laskeneet. Kiintein hinnoin laskien maataloustulo oli vuonna 2004 lähes 34 \% alempi kuin vuonna 1994 (Niemi ja Ahlstedt 2005).

Tämän tutkimuksen tavoitteena on selvittää, miten yhteisen maatalouspolitiikan soveltaminen on vaikuttanut Suomessa maataloustuotteiden tuottajien ja kuluttajien sekä veronmaksajien hyvinvointiin. Taloudessa tapahtuvien muutosten vaikutus yhteiskunnan hyvinvointiin on keskeistä arvioitaessa politiikkamuutosten mielekkyyttä. Hyvinvointivaikutuksia arvioidaan tutkimuksessa käyttämällä hyväksi hyvinvointitaloustieteen (welfare economics) menetelmiä. Hyvinvointitaloustiede on etenkin poliittisen päätöksenteon apuväline (Just ym. 1982). Se pyrkii osana yleistä taloustiedettä antamaan vastauksen kysymykseen "Kuinka poliittiset päätökset vaikuttavat yhteiskuntaan" (Graaf 1967). Hyvinvoinnin mittarina käytetään tutkimuksessa Marshallin (1980) kehittämiä hyvinvointitalousteorian ylijäämäkäsitteitä, joiden avulla arvioidaan euromääräisesti, kuinka paljon kukin ryhmä on politiikan muutoksen seurauksena hävinnyt tai voittanut.

Tutkimus on jaettu viiteen lukuun. Johdantoluvun jälkeen tutkimuksen toisessa luvussa esitellään tutkimuksen teoriaperusta eli tutkimuksen kannalta oleellisin osa hyvinvointitaloustieteestä. Tutkimusaineistoon ja -menetelmään perehdytään kolmannessa luvussa. Neljännessä luvussa esitellään tutkimustulokset ja viidennessä luvussa tuloksista tehdyt johtopäätökset.

\section{Teoreettinen viitekehys}

Kansantaloustieteessä käyttökelpoisin tapa tutkia erilaisten kauppapoliittisten toimenpiteiden asettamisen tai poistamisen (hintatuet, kiintiöt, tullit, vientituet jne.) hyvinvointivaikutuksia on ns. osittaistasapainomalli. Osittaistasapainomallissa keskitytään ainoastaan tietyn hyödykkeen markkinoihin ja näillä markkinoilla tapahtuneen muutoksen aiheuttamat vaikutukset muilla markkinoilla jätetään huomiotta. Pääpaino analyysissa on yksittäiseen tuotteeseen tai tuoteryhmään sovellettujen politiikkatoimenpiteiden vaikutuksissa hintaan, tuotannon määrään, tuloihin ja kauppaan.

Osittaistasapainomallilla on useita hyödyllisiä piirteitä: se on helppo ymmärtää sekä kohtuullisen helppo soveltaa käytännön tutkimuksessa ja sen avulla havaitaan selkeästi minkälaisia taloudellisia vaikutuksia erilaisissa poliittisilla toimenpiteillä on markkinoiden toimintaan. Mallin huono puoli on siinä, että se ei huomioi toisiaan korvaavien ja keskenään kilpailevien hyödykkeiden vuorovaikutussuhteita (Just ym. 1982, Jones 2005).

Kuviossa 1 on esitetty, miten osittaistasapainomallia voidaan käyttää maatalouspolitiikan hyvinvointianalyysissa. Analyysi on staattinen, täydellinen kilpailu vallitsee ja tuotetaan ainoastaan lopputuotteita. Ulkomaiden tarjonnan ja kysynnän hintajousto on ääretön, joten pienen maan oletus on voimassa tarkasteltavana olevan maan kohdalla. Maassa tuotetaan ja sinne tuodaan samaa hyödykettä. Tuonnin kanssa kilpailevan kotimaisen tuotteen oletetaan olevan tuontituotteen täydellinen substituu- 
tio-hyödyke. Tuonnin hinnan oletetaan sisältävän kuljetuskustannukset maahan. Oletetaan lisäksi, että jos kotimaassa tuotetun ja ulkomailta tuodun hyödykkeen hinta on sama, kuluttajat ostavat ensin kotimaassa tuotetut hyödykkeet tällä hinnalla. Tuotteen kysyntäkäyrä on D, kotimaisen tuotannon tarjontakäyrä $S$ ja tuonnin tarjontakäyrä ES.

Lähtötilanteessa tuonnille on asetettu suoja, joka ylläpitää tuottajien ja kuluttajien kotimaan markkinoilla kohtaaman hinnan tasolla $p_{l}$. Tuottajille maksetaan lisäksi suoraa tukea, joka nostaa tuottajien kohtaaman kannustinhinnan tasolle $r_{l}$. Tämä lisää hyödykkeen kotimaista tuotantoa määrään $Q_{l}$. Kulutus on lähtötilanteessa tasapainossa määrällä $C_{l}$ ja hinnalla at $p_{l}$.

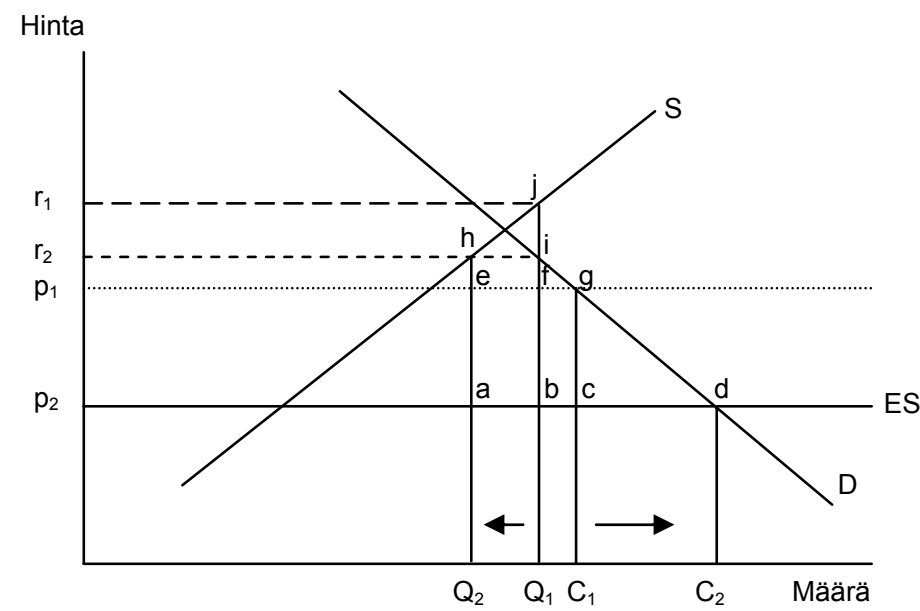

Kuvio 1. Osittaistasapainoanalyysi kaupan vapautumisen vaikutuksista.

Oletetaan nyt, että tuontisuoja poistetaan ja sen seurauksena tuotteen markkinahinta laskee $p_{1}$ :stä $p_{2}$ :een. Tuotteen kulutus nousee alemman hinnan myötä $C_{1}$ :stä $C_{2}$ :een. Tuottajille maksetaan osittaisena hinnan alennuskorvauksena suoraa tukea, $s 2$, joka nostaa tuottajien kannustinhinnan tasolle $r_{2}$. Näin ollen tuottajien kohtaama kannustinhinta laskee kaupan vapautumisen seurauksena tasolta $r_{l}$ tasolle $r_{2}$. Tarjontakäyrältä saatavan reaktion mukaisesti tuottajat laskevat tuotantoaan $Q_{1}$ :stä $Q_{2}$ :een. Vastaavasti tuonti kasvaa $b c$ :stä to $a d$ :hen, kuten nuolet kuviossa 1 osoittavat.

Yhteiskunnan hyvinvoinnin kasvun tai laskun tarkastelu eri markkina- ja politiikka skenaarioissa perustuu siihen, että pyritään laskemaan eri tilanteissa syntyvät edut ja haitat keskenään. Hyvinvointivaikutukset mitataan metodologisesti kuluttajan ja tuottajan hyötyfunktioista. Hyvinvoinnin mittareina käytetään Marshallin (1890) kehittämiä hyvinvointitalousteorian ylijäämäkäsitteitä: tuottajan ja kuluttajan ylijäämää. Taloudellisilla ylijäämäkäsitteillä arvioidaan euromääräisesti, kuinka paljon kukin ryhmä on politiikan muutoksen seurauksena hävinnyt tai voittanut. Hyvinvointitarkastelussa otetaan huomioon myös verorasituksen muuttuminen siirryttäessä hintatuesta suoraan tukeen.

Tuottajan ylijäämällä tarkoitetaan kuviossa 1 tarjontakäyrän ja hintalinjan alapuolelle jäävää aluetta. Tämän alueen koko kuvastaa hyödykkeen tuottajalle tulevan "hyvinvointivoittoa". Kuluttajan ylijäämä on puolestaan hintalinjan ja kysyntäkäyrän väliin jäävä alue. Se voidaan määritellä siksi erotukseksi, joka jää vähennettäessä hyödykkeen markkinahinnasta se hinta, jonka kuluttaja olisi hyödykkeestä enintään valmis maksamaan.

Nämä kaksi taloudellista ylijäämäkäsitettä siis kuvastavat kaupankäynnistä syntyvän hyvinvoinnin lisäystä yhteiskunnassa ja toisaalta sitä, miten se jakautuu tuottajien ja kuluttajien kesken. Vaikka ylijäämäkäsitteitä on arvosteltu niiden puutteiden takia, ne ovat edelleen käyttökelpoinen tapa määrittää eri politiikkavaihtoehtojen vaikutukset yhteiskunnan eri ryhmien kannalta (Bale ja Lutz 1981, Just ym. 1982, Jones 2005).

Tuontisuojan poistaminen kuviossa 1 lisää kuluttajan hyvinvointia alueen $p_{1} g d p_{2}$ verran. Tuottajille kannustinhinnan alennuksesta aiheutuvaksi tappioksi jää alue $r_{j} j h r_{2}$. Alue jih edustaa tehokkuusvoittoa tuotannossa. Veronmaksajille suorasta tuesta aiheutuva kustannus on alue $r_{2} h a p_{2}$, jonka suuruutta on verrattava aiemmin maksettuun alueeseen $r_{l j} f p_{1}$. 


\section{Aineisto ja menetelmä}

Markkina- ja politiikkamuutosten vaikutuksia yksittäisen maataloustuotteen tuotantoon ja kulutukseen arvioidaan tutkimuksessa staattisen osittaistasapainomallin avulla. Mallin lähtökohtana on estimoida tarkasteltavien tuotteiden tuotanto ja kulutus vakiojoustoisten tarjonta- ja kysyntäfunktioiden avulla. EU-jäsenyyden vaikutusten määrittämiseksi vuoden 2003 toteutunutta tilannetta verrataan hypoteettiseen tilanteeseen, jossa Suomi olisi vuonna 2003 ollut EU:n ulkopuolella ja jatkanut kansallisen maatalouspolitiikkansa harjoittamista.

Vaikutuslaskelmat tehdään erikseen kahdeksalle eri maataloustuotteelle: maito, naudanliha, sianliha, siipikarjanliha, kananmunat, vehnä, ohra ja kaura. Näiden tuotteiden osuus Suomen maatalouden markkinahintaisesta tuotosta oli vuonna 2003 yli 90 prosenttia. Laskelmat suoritetaan yhtälöiden 1-8 avulla (Bale ja Lutz 1981):

1) estimoitu maataloustuotanto EU-jäsenyyden ulkopuolella

$$
\mathrm{Q}_{1}=\mathrm{Q}_{2}+\mathrm{n}_{\mathrm{s}}\left[\left(\mathrm{r}_{1}-\mathrm{r}_{2}\right) / \mathrm{r}_{1}\right] \mathrm{Q}_{2}
$$

2) estimoitu maataloustuotteiden kulutus EU-jäsenyyden ulkopuolella

$$
\mathrm{C}_{1}=\mathrm{C}_{2}+\mathrm{n}_{\mathrm{d}}\left[\left(\mathrm{p}_{1}-\mathrm{p}_{2}\right) / \mathrm{p}_{1}\right] \mathrm{C}_{2}
$$

3) nettohyvinvointimuutos tuotannossa EU-jäsenyyden seurauksena

$$
\mathrm{NCB}_{\mathrm{p}}=\left[0.5\left(\mathrm{Q}_{2}-\mathrm{Q}_{1}\right)\right] *\left(\mathrm{r}_{2}-\mathrm{r}_{1}\right)
$$

4) nettohyvinvointimuutos kulutuksessa EU-jäsenyyden seurauksena

$$
\mathrm{NCB}_{\mathrm{c}}=\left[0.5\left(\mathrm{C}_{2}-\mathrm{C}_{1}\right)\right] *\left(\mathrm{p}_{1}-\mathrm{p}_{2}\right)
$$

5) tuottajien hyvinvointimuutos EU-jäsenyyden seurauksena

$$
\mathrm{PS}_{\mathrm{d}}=\left[\mathrm{Q}_{1}-0.5\left(\mathrm{Q}_{2}-\mathrm{Q}_{1}\right)\right] *\left(\mathrm{r}_{2}-\mathrm{r}_{1}\right)
$$

6) kuluttajien hyvinvointimuutos EU-jäsenyyden seurauksena

$$
\mathrm{CS}_{\mathrm{d}}=\left[\mathrm{C}_{1}+0.5\left(\mathrm{C}_{2}-\mathrm{C}_{1}\right)\right] *\left(\mathrm{p}_{1}-\mathrm{p}_{2}\right)
$$

7) muutos veronmaksajien menoissa EU-jäsenyyden seurauksena $\mathrm{TX}_{\mathrm{d}}=\mathrm{Q}_{1}\left(\mathrm{r}_{1}-\mathrm{p}_{1}\right)-\mathrm{Q}_{2}\left(\mathrm{r}_{2}-\mathrm{p}_{2}\right)+\mathrm{EX}_{1}+\mathrm{S}_{2}-\mathrm{TX}_{2}$

8) yhteiskunnan nettohyvinvointimuutos EU-jäsenyyden seurauksena

$$
\mathrm{NSB}_{\mathrm{d}}=\mathrm{NCB}_{\mathrm{p}}+\mathrm{NCB}_{\mathrm{c}}+\mathrm{TX}_{\mathrm{d}}
$$

missä $r_{1}$ on arvioitu tuottajan saama kannustinhinta (markkinahinta + tuet) tuotettua yksikkö kohti EU:n ulkopuolella; $r_{2}$ on tuottajan saama kannustinhinta tuotettua yksikköä kohti vuonna 2003; $p_{1}$ on tuotteen markkinahinta EU:n ulkopuolella; $p_{2}$ on tuotteen markkinahinta vuonna 2003; $\mathrm{Q}_{1}$ on simuloitu tuotantomäärä EU:n ulkopuolella, $\mathrm{Q}_{2}$ on toteutunut tuotantomäärä vuonna 2003; $\mathrm{C}_{1}$ on simuloitu kulutusmäärä EU:n ulkopuolella, $\mathrm{C}_{2}$ on toteutunut kulutusmäärä vuonna 2003, $\mathrm{n}_{\mathrm{s}}$ on tarjonnan hintajousto, $\mathrm{n}_{\mathrm{d}}$ on kysynnän hintajousto, $\mathrm{EX}_{1}$ on maan vientitukimenojen summa vuonna $1994, \mathrm{~S}_{2}$ on EU:n maatalouden ohjaus- ja tukirahastolta (EMOTR) saatujen suorien tukien määrä vuonna 2003, and $\mathrm{TX}_{2}$ on jäsenmaksussa menevä osuus EMOTR:n budjettiin.

Laskelman lähtökohtana on vuoden 2003 tuotanto- ja kulutuslukemat ja hintataso. Tuotantomäärät ovat maa- ja metsätalousministeriön tietopalvelukeskuksen (TIKE) julkaisemasta Maatilatilastollisesta vuosikirjasta, kulutusmäärien lähteinä ovat Maatilatilastollisesta vuosikirjan ravinnetase sekä Suomen Gallup Elintarviketiedon keräämät kulutusluvut. Tuotteiden markkinahinnat ovat MTT Taloustutkimuksen vuosittain laskemasta maatalouden kokonaislaskelmasta. Mallissa tarvittavien tuotekohtaisten tukien laskemiseksi maataloudelle vuonna 2003 maksettu kokonaistuki (1,8 mrd. euroa) on jaettu kokonaisuudessaan Suomessa tuotettujen tuotteiden kesken.

\section{Tulokset}

Tutkimuksen tuottamat tulokset yhteisen maatalouspolitiikan vaikutuksista tuotantoon ja kulutukseen on esitelty taulukossa 1. Vaikutukset tuottajien ja kuluttajien hyvinvointiin on esitelty puolestaan taulukossa 2. Hyvinvointimuutosten suuruus on pitkälti seurausta käytettyjen hintajoustojen arvoista. Mitä joustavampaa tarjonta tai kysyntä on, sitä suuremmat ovat hinnanmuutoksesta aiheutuvat suhteellisen ylijäämän muutokset. Tämän vuoksi tulosten herkkyyttä suhteessa hintajouston suuruuteen tarkastellaan tutkimuksessa käyttämällä sekä matalaa että korkeaa hintajouston arvoa.

Estimoinneissa käytetyt joustojen arvot perustuvat aiemmin tehtyihin tutkimuksiin. Tarjontajoustot on otettu Kolan (1991), Penttilän (1997) ja Niemen (2003) tutkimuksista. Kysyntäjoustot perustuvat Rouhiaisen (1979) ja Laurilan (1994) tutkimuksiin. 
Taulukko 1. Estimoidut muutokset maataloustuotteiden tuotannossa ja kulutuksessa EU-jäsenyyden seurauksena..

\begin{tabular}{lcccc}
\hline & \multicolumn{2}{c}{ Tuotannon muutos } & \multicolumn{2}{c}{ Kulutuksen muutos } \\
Tuote & Matala hintajousto & Korkea hintajousto & Matala hintajousto Korkea hintajousto \\
\hline Vehnä & -2.4 & -6.4 & 10.8 & 29.3 \\
Ohra & -0.5 & -2.4 & 6.4 & 21.9 \\
Kaura & -0.6 & -2.8 & 6.7 & 23.3 \\
Naudanliha & -1.9 & -14.9 & 5.4 & 21.7 \\
Sianliha & 0.0 & -7.3 & 9.3 & 34.1 \\
Siipikarjanliha & -1.4 & -5.5 & 4.3 & 19.9 \\
Kananmunat & -1.8 & -4.5 & 6.1 & 16.8 \\
Maito & -0.9 & -6.1 & 0.2 & 1.7 \\
\hline
\end{tabular}

Laskemalla jokaisen osapuolen - tuottajien, kuluttajien ja veronmaksajien - hyvinvointimuutokset yhteen, saadaan lopputulokseksi koko yhteiskunnan hyvinvointimuutos. Tuottajat ovat kärsineet hyvinvointitapppiota 570-600 miljoonan euroa, kuluttajille on sitä vastoin koitunut 815-875 miljoonaa euroa hyvinvointivoittoa. Veronmaksajien hyvinvointivoitto on puolestaan 470-580 miljoonaa euroa. Eli tutkimustulosten mukaan yhteiskunta on saanut maataloussektorilla EU-jäsenyyden seurauksena noin 500-700 miljoonaa euroa hyvinvointivoittoa.

Taulukko 2. Tuottajien ja kuluttajien hyvinvointimuutokset EU-jäsenyyden seurauksena, milj. euroa.

\begin{tabular}{lcccr}
\hline \multirow{2}{*}{ Tuote } & \multicolumn{2}{c}{ Tuottaja } & \multicolumn{2}{c}{ Kuluttaja } \\
\hline Vehnä & Matala hintajousto & Korkea hintajousto & Matala hintajousto & Korkea hintajousto \\
Ohra & -26 & -27 & 107 & 101 \\
Kaura & -26 & -26 & 106 & 99 \\
Naudanliha & -25 & -25 & 86 & 80 \\
Sianliha & -213 & -229 & 176 & 165 \\
Siipikarjanliha & -135 & -144 & 245 & 223 \\
Kananmunat & -13 & -13 & 67 & 63 \\
Maito & -14 & -14 & 56 & 53 \\
\hline Yhteensä & -118 & -121 & 31 & 31 \\
\hline
\end{tabular}

\section{Johtopäätökset}

Tämän tutkimuksen tavoitteena oli selvittää, miten EU:n yhteisen maatalouspolitiikan soveltaminen Suomessa on vaikuttanut maataloustuotteiden tuottajien ja kuluttajien sekä veronmaksajien hyvinvointiin. Tuottajien ja kuluttajien hyvinvointimuutokset määritettiin estimoitujen tuotanto- ja kulutusmäärien avulla. Hyvinvoinnin mittarina käytettiin Marshallin kehittämiä hyvinvointitalousteorian ylijäämäkäsitteitä, joiden avulla EU-jäsenyyden aikana tapahtunut hyvinvointimuutos pyrittiin määrittelemään euromääräisenä lukuna. Tutkimuksen mukaan tuottajat ovat kärsineet noin 570-600 miljoonan euron hyvinvointitappion EU-jäsenyyden seurauksena. Kuluttajat ovat sitä vastoin saaneet yhteensä 815-875 miljoonaa euroa hyvinvointivoittoa maataloustuotteiden hintojen laskun myötä. Yhteiskunnan hyvinvointimuutoksen määrittämiseen tarvittava veronmaksajien hyvinvointimuutos saatiin vertaamalla tarkasteluvuosina maataloudelle maksettuja tukia. Valtion varoista maksettujen tukien lasku on tuottanut veronmaksajille noin 470-580 miljoonaa euroa hyvinvointivoittoa. Veronmaksajien hyvinvointivoitto on seurausta muun muassa vientikustannusmaksujen siirtymisestä EU:n budjetin kautta rahoitettaviksi. Koko yhteiskunnalle on koitunut EU-jäsenyyden seurauksena noin 500-700 miljoonaa euroa hyvinvointivoittoa. 


\section{Kirjallisuus}

Bale, M. \& Lutz, E. 1981. Price distortions in agriculture and their effects: An international comparison. American Journal of Agricultural Economics 63: 8-22.

Graaff, J. 1967. Theoretical Welfare Economics. London. 171 s.

Jones, C. 2005. Applied Welfare Economics. Oxford: Oxford University Press. 320 s.

Just, R.E., Hueth, D.L. \& Schmitz, A. 1982. Applied welfare economics and public policy. Eaglewood Cliffs: Prentice-Hill, Inc. $85 \mathrm{~s}$.

Kola, J. 1991. Production control in Finnish agriculture: Determinants of control policy and quantitative and economic efficiency of dairy restriction. Maatalouden taloudellisen tutkimuslaitoksen julkaisuja 64. Helsinki. $117 \mathrm{~s}$.

Laurila, I. 1994. Demand for food products in Finland: A demand system approach. Agricultural Science in Finland 3: 315-420.

Marshall, A. 1890. Principles of economics. 8th ed. New York: McMillan.

Niemi, J. 2003. Supply elasticity estimates for farm products. MTT Economic Research, Mimeogr. Helsinki. 9 s.

Niemi, J. \& Ahlstedt, J. (toim.) 2005. Suomen maatalous ja maaseutuelinkeinot 2005 - Kymmenen vuotta Euroopan unionissa. MTT Taloustutkimuksen julkaisuja 105. $94 \mathrm{~s}$.

Penttilä, A. 1997. Suomen EU-jäsenyyden vaikutukset tuottajien ja kuluttajien hyvinvointiin Maatalouden taloudellisen tutkimuslaitoksen selvityksiä 9/97. Helsinki. 44 s.

Rouhiainen, J. 1979. Changes in demand for food items in Finland 1950-77 with consumption forecasts for 1980, 1985 and 1990. Maatalouden taloudellisen tutkimuslaitoksen julkaisuja 40. Helsinki. 84 s. 